\section{Student for a Day}

Kellie E. Johnson, Tara M. King, Roger D. Wessel, and Lisa R. Horst

Many students apply, and are admitted, to two or more colleges or universities during their senior year of high school. Obviously, making an informed decision about which school will best serve the students' needs is essential in ensuring academic and career success beyond high school. One prospective way in which students can make informed decisions is to participate in specially designed programs so they might have a meaningful campus visit and have an opportunity to ask questions about collegiate life.

One such program is at Ball State University which offers a "Student for a Day" program to help admitted students finalize their college choice. The goal of the program is to present both the academic and social aspects of the university so that students can make an informed decision about their possible attendance in the fall.

Upon admission to the university, students are mailed a brochure detailing the "Student for a Day" program, which is offered five times during each spring semester. One is specifically for students admitted into the Honors College, one is for students interested in the "hard sciences" and communications, and the other three are for students considering all other majors. The program agenda is as follows:

\section{Sunday}

\section{5:00. 6:00 p.m. Registration and Welcome}

6:00. 7:00 p.m. Dinner

7:00. 9:00 p.m. Cosmic bowling and Billiards

Meet Ball State host

9:00-10:00 p.m. Move into the Residence Hall with Ball State host

10:00-p.m.

\title{
Monday
}

7:00- 8:30 a.m.

9:00- 9:50 a.m.

10;00-10:50 a.m.

11:00-12:00 noon

12:00-12:30 p.m.

12:30- 1:30 p.m.

2:00- 3:30 p.m.

Students interested in participating in the program enroll by telephone or by returning the form included in the brochure. They then receive a confirmation packet that includes directions to the campus, arrival information, and a behavioral contract stating they will be responsible for their actions throughout the program. Both the student and a legal guardian must sign the contract, which is turned in during registration.

Pre-registered students arrive on campus Sunday evening. During registration, students are given a program agenda, campus map, parking permit, and meal ticket. They are asked to select two university core curriculum classes to attend on Monday morning. After registration and a brief introduction, the admitted students are introduced to a returning student leader who facilitates small-group interaction. The leaders take the students to dinner in a campus dining hall where they participate in icebreakers in order to get acquainted with one another, followed by a trip to the Student Center for cosmic bowling and billiards. Family members also are given the opportunity to have dinner with a campus representative. Music and snacks are available throughout the evening in order to help create a welcoming social environment.

Each year Housing and Residence Life staff identify and recruit on-campus hosts who would be strong representatives of the university, and each host is given a Ball State t-shirt in appreciation of their help with the "Student for a Day" program. These hosts receive training on their role in the program and thus admitted students have more than one positive connection to Ball State University within the first three hours of the program. During bowling and billiards, staff connect participants with Ball State students who will host them in their residence hall rooms overnight. Admitted students are paired with hosts according to gender, smoking preference, and academic major.

Following the bowling and billiards social, hosts take admitted students to their respective residence halls and help them acclimate to the facility. The Residence Hal] Association then sponsors an activity in a residence hall lounge. This organized hall activity is designed to promote social interaction while providing sources of entertainment for the admitted students.

On Monday morning, admitted students eat breakfast in a residence hall dining facility before attending two university classes. Following the classes, students meet with a student panel and have the opportunity to ask questions of current Ball State students. During the closing session, students receive information regarding enrollment deadlines for fall admission and freshman orientation, and are asked to evaluate the program. Each program participant receives a Ball State t-shirt, and an optional lunch and a campus tour completes the program.

Evaluations indicate that many students enjoy having the opportunity to experience campus life first-hand. Sixty-one percent of participants rated the program as excellent Admilted students reported that interacting and meeting with a variety of people on campus was one of the most beneficial aspects of the program. Ninety-three percent indicated that they felt more comfortable with college life after attending the "Student for a Day" program. Eighty-eight percent were very confident or somewhat confident that they would attend Ball State in the fall.

The "Student for a Day" program offers an excellent opportunity for admitted 
students to experience college life and to become acquainted with the university. To ensure that the experience is positive for admitted students, two aspects of the program require special attention. First, there must be excellent communication between, as well as within, all campus offices involved in the program. Miscommunication can result in disorganization that could bave a negative impact on the participants.

Second, the campus leaders and hosts who facilitate the program must be positive. enthusiastic, and comfortable interacting with new people. These leaders have the largest amount of interaction with the admitted students, and therefore strongly impact their views of the university. With communication and strong leadership, the "Student for a Day" program can be an excellent addition to any college or university's admitted student programs.

\section{BOOK REVIEW}

Daniel P. Nadler, Associate Editor

\section{Empty Nest...Full Heart: \\ The Journey From Home to College}

By Andrea Van Steenhouse, Ph.D.

Denver, CO: Simpler Life Press, 1998, 183 pages

Reviewed by

Brenda L. McKenzie

The field of literature targeted at parents and families of incoming students is growing. One recent addition to this market is Empry Nest...Full Heart: The Joumey from Home to College by Andrea Van Steenhouse, Ph.D. The author presents information on the experiences of students and parents from the beginning of the senior year in high school into the first year in college.

The introduction to the book expresses this experience as a rite of passage. The author highlights how all the moments of child rearing are leading to this point - "to produce loving, competent, responsible adults" (p.5). This time and these experiences are portrayed as a journey - which is certainly something to which parents can relate.

Section 1 - "That Incomparable Senior Year" - traces the emotions and activities of the senior year. Van Steenhouse provides a very comprehensive overview of how senors behave and the joys and frustrations of their parents during this time. She acknowledges that different students will have different experiences. All parents, however, will have to face the sense of power seniors develop as an extension of the freedom and privilege provided them. Van Steenhouse accurately discusses that both parties will experience mixed emotions and that letting go is a gradual process. However, she portrays seniors as power-hungry beings who completely dismiss any structure in their lives. While some of this is definitely true, she allows for no middle ground where many students land. One key point that is made repeatedly is the need for parents to listen carefully. During the senior year, listening can be overlooked due to the limited time available to spend with the student.

Selecting a college is a major stage in the development of a senior's decision-making skills. Ambivalence is most likely to become an issue at home around this topic. Vari Steenhouse presents a fairly accurate picture of the pains of the college selection process She also addresses the industry of college consultants. The use of consultants as she describes it, however, does not take into account traditional aspects of a selection process such as "fit." Stress is a regular part of this decision making process, along with hope and expectancy. 